\title{
The Role of Decision Making for Family Activities by Industrial Labour of Women Migrant Based on Their Migration Characteristics
}

\author{
Dewi Susilongtyas ", Tuty Handayani, Nurul Sri Rahatiningtyas, Sigit Candra Winata Kusuma, \\ Della Ayu Lestari \\ Department of Geography, Faculty of Mathematics and Natural Sciences, Universitas Indonesia \\ *) Corresponding Author (dewi.susiloningtyas@sci.ui.ac.id)
}

Received: 29 Juli 2019/ Accepted: 17 Januari 2020 / Published: Juli 2020

\begin{abstract}
The presence of women migrants in urban industrial workers proved that women's movement exists. This migration process not only indicates that women are actively involved in economic activity but also influences the decision-making on important activities within the family and society. This study aims to determine the relationship between mobility patterns and its contribution to economic and decision-making in the family through the survey as research methods. The data were analysed by descriptive analysis, statistics approach, and correlation maps. For the independence test in the bivariate table, we used the chi-square method, and to display the distribution of two variables simultaneously, a cross-tabulation was used. After that, to assess whether there is a relationship between the two variables, the table of independence was used. Our study shows that decision-making became an indicator of strengthening the role of women with a pattern of circular migration, which has a relationship on economic contribution. However, the behavior of women who perform the spatial migration in strengthening roles in families is not always relevant to the strengthening role of the economy. A strong role is only demonstrated by industrial migrant workers working on a circular migration pattern.
\end{abstract}

Keywords: women, decision-making, migration, migrant

\section{Introduction}

Population dynamics that reflect the inter-regional relations is increasing at the present time. This phenomenon emerges due to various factors, including the increase of transportation accessibility, communication, and the need to interact with individuals and communities. Such movements not only affect to social aspect but also the environmental aspect. Socially, population mobility enriches their social network that helps to increase social interaction (Herz et al., 2019), where the interaction between the environment and the dynamics of the human population can affect to the variability of environmental development such as ca be observed from landuse changes (Dadashpoor et al., 2019).
Population mobility is an inseparable part of the development process. Mobility has been the cause change from the dynamics of the economic and social structure of an area. Moreover, migrations are triggered by the variability of economic growth among regions. This describes why the migration phenomenon is decreased in one area, while this is increased in the other regions. Economics and livelihood are the most important factors among the various motivation of human migration (Dickenson et al., 1992). The increment of interaction between regions can be indicated by a large number of population movements from one region to another, such as short-term movement (circulation) (Dickenson et al., 1992). 
The process of moving from one region to another or one place to another is called migration. Migration is mostly conducted by males than females as part of the role to earn a living and actively involved in economic activities. But, as the higher demands of life, the female population begins to play a role in conducting economic activities with the consequence of leaving her home and family. The population movement is a normal response and expected to occur because the economic changes in the city will also affect the economic changes in the area of origin, including the improvement of family welfare.

The fact is that women involved in earning have a relation to the role of women in determining their family planning/decision. The role of women in determining patterns and forms of kinship in the family and also with the community outside becomes very interesting to be analysed. Therefore, the aspect that became part of this research is to describe and analyse how the role of women in determining the future and the process of social and economic activities in their family.

As the most growing city, Jakarta becomes the main destination of population mobility. Jakarta becomes a strong attraction for residents from outside of Jakarta to find employment. Therefore, it is not surprising that almost the majority of the population, nearly $50 \%$, are migrant-people. The urban fringes of Jakarta, such as in Depok City, become highly developed for industrial purposes because of the increasing land demand in Jakarta (Ilahi et al., 2019). Consequently, the industrial corridor of Jakarta Bogor street is an industrial area that developed due to the attractiveness of the location.

A large number of industrial activities located in the Jakarta Bogor corridor has led to an increase in the number of lodgings for migrant industrial workers. In the administrative area around this corridor, precisely in District Sukmajaya, almost most of the houses in this area are rented or leased. This indicates that there are a large number of the migrant population, especially women who work in the industrial sector (Muhidin, 2014).

Studies on this phenomenon have been widely conducted, such as by Williams (2019), Hendrickson (2019), Tong et al. (2019), Luna et al. (2019) and Grabe (2020). However, similar studies in Jakarta with the complexity that differ from other regions are missing from the literature. This research will examine how their migration patterns are related to their interactions with their home-based family, both economically and socially, in this region. This is measured based on the role of migrant industrial workers in income, remittances, and decision making within their family.

\section{Methods}

As this study would like to explore the role of industrial migrant workers, we tested the relationship between economic contribution in the family and the role of decision making in the family. Decision-making means in terms of family activities, as well as future decisions of the family (Manchin \& Orazbayev, 2018). The research approach for data collection surveys with questionnaires and guided interviews. Preparation for the survey included the determination of the location of the research, variables, as well as the respondents.

The research area is Industrial Area on Jakarta Bogor streets, which is included Sukmajaya and Cimanggis Subdistrict in Depok City. The respondents are female workers who have work status as migrants and work in big industries. We considered two categories of respondents, who migrate in circulation mobility and in shuttle mobility or commute. The variables to determine migration patterns (migrants' regions) are the economic role of the family (remittances and income), and decision on family activities (domestic family decisions, future family decisions, and social decisions in society). The domestic decisions were categorized by decisions on daily purchasing activities, determining children's schooling, recreational purposes, buying household appliances, and doing housekeeping activities. Future family decisions were grouped by decisions in home buying activities, buying 
land, and determining spouses. In addition, social decisions in society are determined by community service works, community meetings, donations, and the selection of community leaders.

The technique of data analysis is descriptive and statistical analysis, including correlation. Methods for determining roles are used in descriptive analysis techniques with categorization, while for strengthening the relationship of roles, we used statistical analysis with Chi-Square Test, which tested the relationship between an economic role (income and remittances) with family decision making. Chi-Square results will also be made on the results of the tables of Chi-Square.

Techniques in determining the role of family decision making are grouped by categories of female dominance in decision making. Types of decision making are divided into three types of decision making. The data then classified into three categories based on who plays a role in decision making including (1) self-decision category (woman): where decisions are taken by migrant women, (2) category of collective decision: where decisions are made together from all existing family members, (3) the decision category of family members: where decisions are made by one in the family other than the women of the migrant industry workers themselves.

The statistical analysis of Chi-Square (Equation 1) is expected to find out whether there are differences in decision making on women migrant workers, who have high income and high, medium, and low remittance rates. The pre-defined hypothesis (Ho) is that there is no relationship between income level and remittance to family decision making.

$$
\begin{aligned}
& \mathrm{X}^{2}=\frac{\Sigma(0-\mathrm{E})^{2}}{\mathrm{E}} \\
& 0=\text { observation } \\
& \mathrm{E}=\mathrm{n} \text { expected } \\
& \mathrm{Df}=(\mathrm{b}-1)(\mathrm{k}-1) \\
& \mathrm{b}=\text { number of line } \\
& \mathrm{k}=\text { number of column }
\end{aligned}
$$

\section{Results and Discussion}

The corridor of the Jakarta Bogor highway industry is a centralized area of industrial activity that is not regulated in single management, such as an industrial estate. It was growing with various industrial activities due to the attractiveness of the location. It also was once a very strategic suburban of Jakarta for industrial activities, namely the accessibility of roads and other industrial support facilities. It was not surprising that every year before the availability, this area has a great demand for the establishment of industrial sites. The research area is a segment within this corridor that was included in the Sukmajaya District administration as below (Figure1).Land development in the segment of the industrial corridor in Sukmajaya that included in the study area was mostly for economic activities and settlement areas. The rapid development of industry has influenced socio-economic services growth, such as shops, settlements, educational, and health facilities in this area.

\subsection{Migration Pattern of Migration Areas}

West Java Province, which has adjacent administrative boundaries and has relatively proximity to Depok City, has the highest number of female industrial workers, who perform circular migration (Figure 2a). It indicates that circular migration is carried out by people who have migrant origin areas at a short distance, followed by migrations from Central Java and East Java Provinces.

The difference in migration patterns can be seen from the migration flow for the shuttle pattern (Figure 2b). From this Migration Flow Map, it shows that female workers had experience shuttle migration around Jakarta, Bogor, and other sub-districts in Depok City, including Sukmajaya. From this map, it was also seen that the migration pattern was dominated by people from Depok who cross the district administration, followed by Bogor and Jakarta. These different patterns of migration flow will be seen in the number of transportation costs by the migrant workers. The migrant workers who cross more closely administrations will spend lower transport costs. 


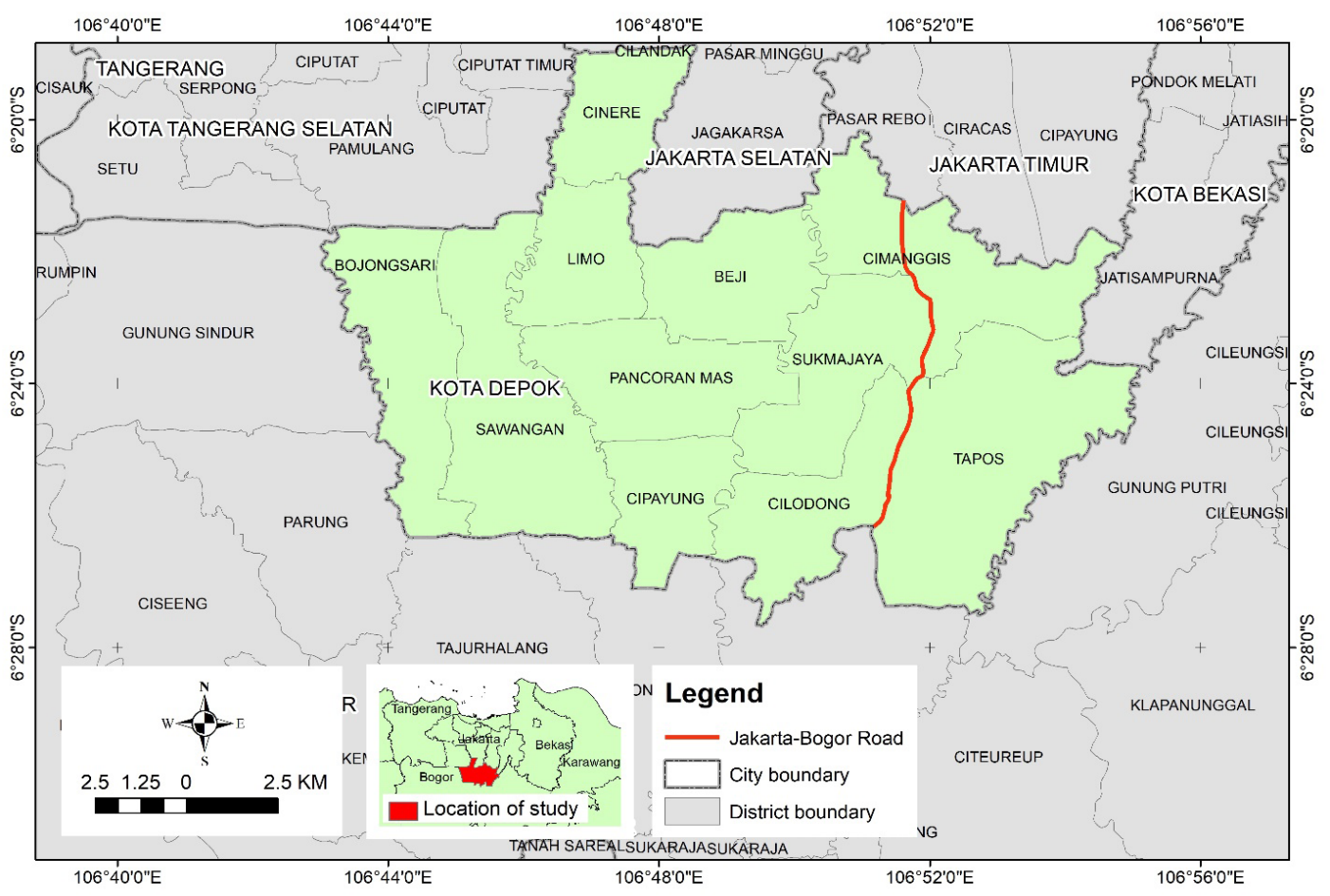

Figure1. Study Area
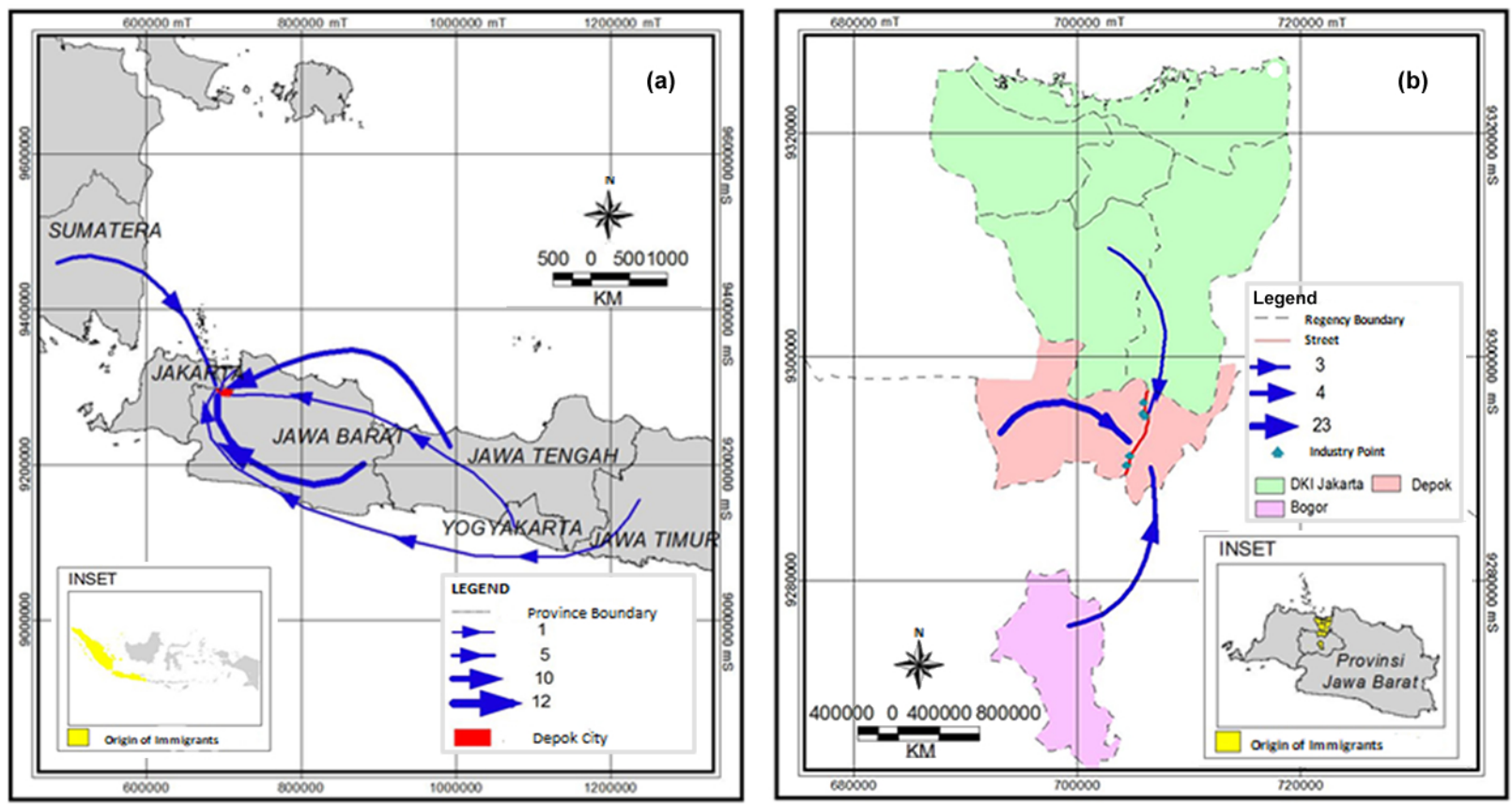

Figure 2. Migrant flow pattern. (a) Circular migration flow from migration areas. (b) Commuter migration flow from areas of origin

3.2 Behaviorand Role of WomenEconomics of a significant relationship between the high of Migrant Industry in Family Decision economic roles inevitably followed by the Making

The role strengthening in the family can be seen from the economic contribution of each individual in the family. The assumption dominant family decision making that will be demonstrated in this research (Yakita, 2019). The results showed that between the economic roles of women who are doing the pattern of 
circular migration and women with the pattern of shuttle migration (Timár \& Velkey, 2016). The economic role that becomes indicator is the remittance to the area of origin and income level. The money items (in Rupiah) are categorized high level $(>1,000,000)$ remittance, medium level $(500,000-1,000,000)$, and low level $(<500,000)$. The income level was categorized as follows: high revenue $(>1,500,000)$, moderate $(1,000,000-1,500,000)$, and low $(<1,000,000)$.

Other research shows that paying attention to the dynamics of the pattern of the family's role in TV purchasing; for example, the dominant initiator, was held by the wife. The role of influencer shows the level of equality by each family member in influencing. Compared to other family members, the husband holds the role of a buyer. At the same time, the role of a user is largely held by the child and husband as the second user in the family, if this is seen as the role of people (Helmi, 2017).

\subsection{Correlation between Remittances and} Behavior of the Domestic Decision Role

This relationship can be explained in the correlation matrix, such as: if the role of women in decision-making related to the fulfillment of domestic needs is attributed to the magnitude of their remittances to the family in the area of origin, then it can be concluded that the lower value of remittances to the hometown, circular migrant workers tend to make their own domestic decision-making or decision on their own $(77 \%)$.

Table 1. Percentage Decision of Domestic Roles Based on Remittances

\begin{tabular}{cccc}
\hline & \multicolumn{2}{c}{ Domestic Decision Role (\%) } \\
\hline & Migrant & Together & $\begin{array}{c}\text { Members } \\
\text { of Family }\end{array}$ \\
\hline High & 0 & 0 & 3 \\
Moderate & 10 & 0 & 0 \\
Low & 77 & 3 & 7 \\
\hline
\end{tabular}

As for the higher the value of remittances to their hometown, circular migrant workers tend to rely on one other family member, dominant in their domestic decision making, such as the decision of the category taken by one family member $(3 \%)$. This can be seen in Table 1 . From these results, it appears that the economic role in a high family is not always followed by the dominant decision-making role.

Based on the result of the statistical analysis, it was mentioned that with a significance level $(\alpha)=0.05 \%$, the result is the Chi-Square value (14.82) which is bigger than Chi-Square table (between the remittances to family in the area of origin and domestic decision-making activities). It is supported by the value of p-value (0.005), which is smaller than its a value. The conclusion of all is that the magnitude of remittances of migrant workers' industrial migrants' influence on their role in the family decision making for domestic activities.

\subsection{Correlation between Remittances and Behavior of Family's Future Decision Role}

A similar pattern exists in the relationship between the level of remittances and future family decision making (Zhong \& Arnett, 2018) The results of the correlation matrix table indicate that many self-made decisions by migrant women are on the migration pattern with the low rate of remittance to the origin of $77 \%$, while the next sequence is on the decision made by the family members, who another $7 \%$, while those taken together by the whole family are $3 \%$ (result can be seen in Table 2). So, it can be concluded that the lower value of remittances to home, circular migrant workers tend to make decisions for the future of his family. While the higher value of remittances to their villages, the circular migrant workers tend to depend on others in making future decisions of their families.

The relationship between remittances and decision making is also reinforced by statistical analysis. Chi-Square test results showed that Chi-Square count $(9,630)$ bigger than chisquare table with value $\alpha=0.047$ at $d f=12$. From this data $p$-value value is smaller than value o (0.005), meaning that Ho is successfully rejected, so it is stated that there is a relationship 
between remittances and women's decision making in activities about the future of the family, which also means that the magnitude of remittances affects women in the family decision making.

Table 2. Percentage Decision of Family's FutureRole Based on Remittances

\begin{tabular}{cccc}
\hline & \multicolumn{2}{c}{ Family's Future Decision Role (\%) } \\
\hline & Migrant & Together & $\begin{array}{c}\text { Family } \\
\text { Members }\end{array}$ \\
\hline High & 0 & 0 & 3 \\
Moderate & 10 & 0 & 0 \\
Low & 77 & 3 & 7 \\
\hline
\end{tabular}

Data about variables is often collected in categories that can be summarized as a series of calculations in research. The format of a table known as a contingency table is usually arranged in this calculation. The chi-square test statistics can be used to evaluate whether there is a relationship between rows and columns in a contingency table. More specifically, chisquare can also be used to determine whether there are differences between study groups in the proportion of risk factors. The chi-square includes a series of tests that measure how expectations compare with the actual data observed (or the results of the model) is also one method of using chi-square statistics $\left(x^{2}\right)$ (Rana, 2015).

\subsection{The Relationship between Money} Submissions and the Societal Decision Making Behavior

The results obtained about the relationship between remittances to the origin and the role of decision making in the social activities of the community turned out to indicate a relationship. This statement is supported by the statistical result (chi-square value of 14,822 ) which is bigger than chi-square table at value $\alpha=0.005$, with $\mathrm{df}=12$, so that chi-square test did successfully reject Ho, which means there is a relationship between the amount remittances made with decision making in the social community. This correlation is shown by the relationship, which is the higher the money transfers, the lower the role of women in the decision-making will undertake, instead it is dominated by joint decision making by all family members. Conversely, the lower the money remittance to the area of origin, the higher the role of women in decision-making of social activities in their community. This means that although remittances are little, their role in social decision-making remains high. The percentage of social community decision-making based on remittances can be seen in Table 3.

Table 3. Percentage of Social community Decisionmaking Based on Remittances

\begin{tabular}{cccc}
\hline & \multicolumn{3}{c}{ Social community Decision-making (\%) } \\
\hline Migrant & Together & $\begin{array}{c}\text { Family } \\
\text { Members }\end{array}$ \\
\hline High & 0 & 3 & 0 \\
Moderate & 10 & 0 & 0 \\
Low & 77 & 3 & 7 \\
\hline
\end{tabular}

\subsection{The Relationship between Income} Level and Family Domestic DecisionMaking Behavior

In this study, the income level can be an indicator of how big the role of women migrant industry workers in the family economy, especially for the pattern of commuter or shuttle migration. By examining the relationship between migration pattern based on income level and the magnitude of the role in decision- making, it can be seen how the relationship patterns occur, but it can also be known whether there is a significant relationship between these two variables.

The results of this study can be seen in Table 4 , indicate that the role of decision making in the family when viewed from the income level is that women with high-income level have the highest role in domestic decisionmaking by themselves, that is equal to $53.3 \%$, followed by female migrant low income, at $16.7 \%$, and moderate-income, at $13.3 \%$. This means that the higher the economic role of women, the more involved in domestic family activities. 
Table 4. Percentage of Decision-making based on Income

\begin{tabular}{cccc}
\hline & \multicolumn{3}{c}{ Domestic Decision-making (\%) } \\
\hline & Migrant & together & $\begin{array}{c}\text { Family } \\
\text { Members }\end{array}$ \\
\hline High & 53. & 16.7 & 0 \\
Moderate & 13.3 & 0 & 0 \\
Low & 16.7 & 0 & 0 \\
\hline
\end{tabular}

As if seen from the relationship between income and decision-making can be strengthened by the Chi-Square test. From a result of analysis with Chi-Square, it can be seen that Chi-Square count $(2,571)$ smaller than the chi-square table at the level of significance $(\alpha)=0.05$. On the probability level, it appears that $p$-value $(0.276)$ is greater than $a=0.05$ so that the relationship between income level and domestic family decision making statistically fails to reject Ho (accepting Ho), meaning that there is no significant relationship. The conclusion of the relationship between the two is that domestic family decision making conducted by female migrant workers in the study area has no relationship with the amount of income.

Women were given selective information (incomplete/biased towards recurrent cesarean) and relative risk formats (incidence ratio compared to 2.5 times higher) compared with other studies. A lower risk for recurring faults rather than repetitive faults provided with non-selective information (complete/ unbiased) and absolute risk formats (event rates eg 0.01 per 100). Labor preferences will not affect the role of decision making in a significant way (Miller \& Holdaway, 2019).

\section{The Relationship between Income Level and} Family Decision Making Behavior

The role of women in decision-making for the family's future on the basis of income levels shows that women with high incomes have the most dominant decision, at $43.3 \%$. The decision made by the next woman is in the category of low-income women, which amounted to $16.7 \%$. While for the decision of category 1 that is done by itself, the lowest level is in women with a medium-income level that is only $10 \%$. Collective decision-making with other family members was also dominated by women with high incomes of $26.7 \%$. This suggests that the high incomes of women migrant industry workers have a high role in the family's own future decision making by women. These results can be seen in Table 5 .

Table 5. Percentage of Decision-Making for Future Family Based on Income

\begin{tabular}{lccc}
\hline \multicolumn{3}{c}{ Decision-making for Future Family (\%) } \\
\hline & Migrant & Together & $\begin{array}{c}\text { Family } \\
\text { Members }\end{array}$ \\
\hline High & 43.3 & 26.7 & 0 \\
Moderate & 10.0 & 3.3 & 0 \\
Low & 16.7 & 0 & 0 \\
\hline
\end{tabular}

The result of strengthening the relationship with chi-square states that the calculated chisquare $(2,846)$ is smaller than the chi-square table at $a=0.05$ with degrees of freedom 2 . The p-value (0.241) is greater than a value, thus failing to reject $\mathrm{H} 0$. This means that future family decision making by migrant industry workers is not related to the amount of income.

The Relationship between Income Level and Social Responsibility Decision Behavior

Social decision making in society can be indicated as the involvement of women in various activities in the community, such as community service activities in the environment, attendance at community meetings, participation in choosing leaders, and involvement in donations and social actions. The results in Table 6 showed that women with high-income levels relatively have a high role for decision making by themselves that is equal to $40.0 \%$. In this social activity, there are decisions made by family members outside the migrant women, ie, by one of the family members in the house, the husband that is $13.3 \%$ for the category of high-income female families and $3.3 \%$ for medium income. This shows that in the social activities of women's 
role is not dominant, but already involving the decision together and one of the family, like a husband.

Table 6. Percentage of Decision-making Social Community Based on Income

\begin{tabular}{cccc}
\hline \multicolumn{4}{c}{$\begin{array}{c}\text { Decision-making of the social } \\
\text { community (\%) }\end{array}$} \\
\hline Migrant & Together & $\begin{array}{c}\text { Family } \\
\text { Members }\end{array}$ \\
\hline High & 40.0 & 16.7 & 13.3 \\
Moderate & 10.0 & 10.0 & 3.3 \\
Low & 16.7 & 0 & 0 \\
\hline
\end{tabular}

The result of the chi-square test stated that the chi-square value $(5,188)$ is still smaller than the chi-square table at $\alpha=0.05$ with $\mathrm{df}=$ 4. It is also supported by the value of $a$, which is still smaller than the p-value (0.269). The obtained result is that the statistical test fails to reject Ho, so it must accept Ho. Therefore, the conclusion on the relationship between income and social decision-making society is that decision-making is not significantly related to the amount of income.

We found that households, when the decision-making responsibilities were the responsibility of women, would have lower deprivation rates regardless of income levels at the time compared to other studies using the European Union Statistics on Income and Living Conditions (EU-SILC) dataset. Conversely, when decisions are taken, and women are not fully involved, greater levels of deprivation are more likely to occur in the household. This finding highlights the importance of integrating family arrangements in managing actions aimed at reducing inequality and increasing the general economic well-being of women (Bárcena-Martín et al., 2020).

\section{Conclusion}

The behavior of women who perform the spatial migration in strengthening roles in families is not always signed with the strengthening role of the economy. A strong role is only demonstrated by industrial migrant workers working on a circular migration pattern. Chi-square test results indicate that there is a relationship between family behavior in their decision-making with the economic contribution given to the area of origin, it will be domestic decision-making, future family, and decision-making related to the social community. In contrast, women with a pattern of shuttle migration using income level as indicators. The provided economic contribution does not have a significant relationship in family behavior decision-making.

\section{Acknowledgment}

Thanks to the Directorate of Research and Community Service UI, who has provided research funding through the Initial Grant.

\section{References}

Bárcena-Martín, E., Blázquez, M., \& Moro-Egido, A. I. (2020). The role of income pooling and decision-making responsibilities in material deprivation. Economic Modelling, 87, 416-428.

Dadashpoor, H., Azizi, P., \& Moghadasi, M. (2019). Land use change, urbanization, and change in landscape pattern in a metropolitan area. Science of The Total Environment, 655, 707-71

Dickenson, J.P.et.all.(1992).Geography of Developing Countries. Semarang: IKIP Semarang Press.

Grabe, S., Rodríguez Ramírez, D., \& Dutt, A. (2020). Reproductive Justice: The Role of Community $\square$ Based Organizational Participation in Reproductive Decision $\square$ Making and Educational Aspirations among Women in Nicaragua. Journal of Social Issues.

Helmi, Arief. (2017). Pembagian Peran Dalam Pengambilan Keputusan Pembelian Keluarga. Prosiding Seminar Nasional Multi Disiplin Ilmu \& Call For Paper UNISBANK Ke-3. ISBN: 9-789-7936-499-93 464. Bandung: Prodi Manajemen, Fakultas Ekonomi \& Bisnis Universitas Padjadjaran. 
Hendrickson, Z. M., Owczarzak, J., Lohani, S., Thapaliya Shrestha, B., \& Underwood, C. R. (2019). The (re) productive work of labour migration: the reproductive lives of women with an absent spouse in the central hill region of Nepal. Culture, health $\mathcal{E}$ sexuality, 21(6), 684-700.

Herz, A., Díaz-Chorne, L., Díaz-Catalán, C., Altissimo, A., \& Carignani, S. S. (2019). Are you mobile, too? The role played by social networks in the intention to move abroad among youth in Europe. Migration Letters, 16(1), 93-104.

Ilahi, A., Balac, M., Li, A., \& Axhausen, K. W. (2019). The first agent-based model of greater Jakarta integrated with a mode-choice model. Procedia Computer Science, 151, 272-278.

Luna, S. S., \& Rahman, M. M. (2019). Migrant wives: dynamics of the empowerment process. Migration and Development, 8(3), 320-337.

Manchin, M., \& Orazbayev, S. (2018). Social networks and the intention to migrate. World Development, 109, 360-374.

Miller, Y. D., \& Holdaway, W. (2019). How communication about risk and role affects women's decisions about birth after caesarean. Patient education and counseling, 102(1), 68-76.

Muhidin, S. (2014). 13 Migration patterns: people on the move. Regional dynamics in a decentralized Indonesia.

Rana, Rakesh Kumar. (2015). Chi-square Test and its Application in Hypothesis Testing. Central Council for Research in Ayurvedic Science.

Timár, J., \& Velkey, G. (2016). The relevance of the political economic approach: The interpretations of the rural in the migration decision of young women and men in an economically backward region. Journal of Rural Studies, 43, 311-322.

Tong, Y., Shu, B., \& Piotrowski, M. (2019). Migration, livelihood strategies, and agricultural outcomes: A gender study in rural China. Rural Sociology, 84(3), 591-621.

Williams, L. B. (2019). Development, demography, and family decision making: The status of women in rural Java. Routledge.

Yakita, A. (2020). Economic development and long-term care provision by families, markets and the state. The Journal of the Economics of Ageing, 15, 100210.

Zhong, J., \& Arnett, J. J. (2018). “I felt like there would be a vast sky out there" The leaving home decisions of Chinese migrant women workers. International Perspectives in Psychology: Research, Practice, Consultation, 7(3), 121. 